(2) 


\title{
WILHELM MEISTER
}

\author{
Das Ende der Kunst
}

und die Wiederkehr des Mythos

J. B. Metzlersche Verlagsbuchhandlung

Stuttgart 
CIP-Kurztitelaufnahme der Deutschen Bibliothek

Schlaffer, Hannelore:

Wilhelm Meister: d. Ende d. Kunst u. d. Wiederkehr

d. Mythos / Hannelore Schlaffer. - Stuttgart:

Metzler, 1980.

ISBN 978-3-476-00453-6

ISBN 978-3-476-00453-6

ISBN 978-3-476-03139-6 (eBook)

DOI 10.1007/978-3-476-03139-6

(c) Springer-Verlag GmbH Deutschland 1980

Ursprünglich erschienen bei J. B. Metzlersche Verlagsbuchhandlung und Carl Ernst Poeschel Verlag GmbH in Stuttgart 1980 
Das Buch von Hannelore Schlaffer über Goethes Wilhelm Meister und das von Heinz Schlaffer über Faust II sind komplementär im Kontrast. Für ihre unterschiedlichen Methoden und Ergebnisse sind nicht gegensätzliche Vorentscheidungen der Verfasser, sondern spezifische Anforderungen der poetischen Werke verantwortlich.

Die Wilhelm-Meister-Philologie vertraute bislang dem zeitnahen Vordergrund des Werkes, so daß die Ikonologie seines mythologischen Hintergrundes unentdeckt blieb. Die Faust II-Philologie hielt sich vornehmlich an den mythologisch-symbolischen Apparat und ließ die historischen Bedeutungen unbedacht.

Die vorliegenden Abhandlungen kehren die Richtung der Erkenntnis um: Die Interpretation der Wilhelm-Meister-Romane findet in verborgenen Bildern einen Sinn, der die Prosa des Wirklichen überschreitet. Die Interpretation von Faust II entdeckt die Allegorie als die bildliche Form der Abstraktionen, von denen Goethe das Jahrhundert bestimmt sah.

Die unterschiedlichen Interpretationsverfahren berücksichtigen die historisch begründete Wandlung von Goethes ästhetischer Konzeption. Seine Wilhelm-Meister-Romane waren in der Hoffnung geschrieben, daß Erfahrungen der bürgerlichen Moderne an die Bilder wiederkehrender Mythen zurückzubinden seien. Faust II, Goethes letztes Werk, geht aus der Einsicht hervor, daß die Ansprüche der Moderne seinen Bildervorrat übersteigen und eine neue ästhetische Antwort verlangen. Die Mythen werden von der Allegorie aufgebraucht. Gerade die thematische Nachbarschaft von Wilhelm Meisters Wanderjahren und Faust II macht die geschichtliche Notwendigkeit der poetischen Alternativen bewußt. 
INHALT

Einleitung: Wortsinn und Mythos $\ldots \ldots \ldots \ldots \ldots \ldots \ldots$

Erster Teil: Kunst

1. Imitationen. Die Orphik $\ldots \ldots \ldots \ldots \ldots \ldots \ldots \ldots . \quad 17$

Am Lago Maggiore $\ldots \ldots \ldots \ldots \ldots \ldots \ldots \ldots \ldots \ldots \ldots . \ldots \ldots$

Sankt Joseph der Zweite .................. 26

Exkurs: Vergangenheit und Erinnerung

in der Ästhetik des 18. Jahrhunderts ............. 34

2. Das Ende der Kunst. Neuplatonismus ......... 40

Mignon und der Harfner $\ldots \ldots \ldots \ldots \ldots \ldots \ldots \ldots . . \ldots$

"Die pilgernde Törin «. "Ottilien von Goethe «........ 51

Der Saal der Vergangenheit. »Laßt mich scheinen,

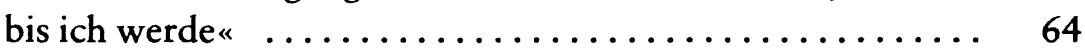

Exkurs: Mignon als Psyche $\ldots \ldots \ldots \ldots \ldots \ldots \ldots \ldots .75$

3. Schein und Sein. Seele und Form ............ 80

Maskeraden und Rollenspiele $\ldots \ldots \ldots \ldots \ldots \ldots \ldots \ldots . \quad 80$

"Der Mann von funfzig Jahren « .............. 91 
Zweiter Teil: Medizin

1. Schönheitssinn und Altruismus .............. 111

Wilhelms Studium der Anatomie $\ldots \ldots \ldots \ldots \ldots \ldots \ldots, 111$

"Im ersten Beinhaus war's «. "Vermächtnis « .......... 120

Der ertrunkene Freund $\ldots \ldots \ldots \ldots \ldots \ldots \ldots \ldots \ldots, 128$

Exkurs: Sinnlichkeit und Verstand, Poesie und Prosa ..... 134

Kunsterziehung in der Pädagogischen Provinz. Der »Alte “ . 142

2. Mythologie der Medizin .................. 153

Minerva und Äskulap ..................... 153

"Kennst du das Land, wo die Zitronen blühn « ....... 160

Kastor und Pollux ..................... 166

3. Mysterien der Erlösung. Kosmische Dichtung ....... 175

Eleusis. "Nicht zu weit " .................. 175

Makarie und Montan ................... 183

Schluß: Der fiktive Herausgeber und der wirkliche Autor.

"Wer ist der Verräter?" ................... 196

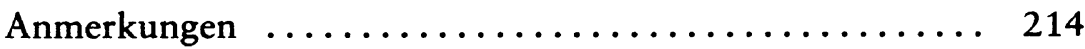

Verzeichnis der zitierten Literatur .............. 244 